Relations industrielles

Industrial Relations

\title{
À la mémoire de Lise Poulin Simon, 1937-1995
}

Diane Bellemare et Ginette Dussault

Volume 51, numéro 1, 1996

URI : https://id.erudit.org/iderudit/051072ar

DOI : https://doi.org/10.7202/051072ar

Aller au sommaire du numéro

\section{Éditeur(s)}

Département des relations industrielles de l'Université Laval

\section{ISSN}

0034-379X (imprimé)

1703-8138 (numérique)

Découvrir la revue

\section{Citer ce document}

Bellemare, D. \& Dussault, G. (1996). À la mémoire de Lise Poulin Simon, 1937-1995. Relations industrielles / Industrial Relations, 51(1), 4-4.

https://doi.org/10.7202/051072ar

Tous droits réservés @ Département des relations industrielles de l'Université Laval, 1996
Ce document est protégé par la loi sur le droit d'auteur. L’utilisation des services d'Érudit (y compris la reproduction) est assujettie à sa politique d'utilisation que vous pouvez consulter en ligne.

https://apropos.erudit.org/fr/usagers/politique-dutilisation/ 


\section{À la mémoire de Lise Poulin Simon, 1937-1995}

En août dernier, nous perdions une collègue et amie, Lise Poulin Simon. Nous voulons ici rendre hommage à cette femme énergique, engagée, généreuse et courageuse en soulignant la cohérence de son parcours intellectuel.

Lise s'est engagée dans des études universitaires en sciences économiques alors qu'elle avait déjà fondé une famille et avait deux jeunes garçons. Cette maturité l'a amenée très tôt à contester la vision néoclassique de l'économie. En particulier, ses critiques de l'arbitrage travail-loisirs qui présente le travail comme une nuisance furent le début de ses préoccupations de recherche et l'inspiration directe de son doctorat. Sa thèse analysait l'évolution de la réduction du temps de travail et a mis en évidence que l'accélération de la réduction du temps de travail coïncidait avec des périodes de pénuries d'emplois. Lise montra comment ces réductions se sont faites sous la pression des représentants des travailleurs, ce qui lui permit de préciser une orientation théorique durable : la lutte à l'insécurité économique est un moteur puissant de l'action collective sur le marché du travail.

Par la suite, son analyse de la problématique de l'assurance vs l'assistance sociale a renforcé ses convictions entourant l'importance de l'emploi rémunéré. En effet, l'assurance sociale ne peut répondre adéquatement au problème de l'insécurité économique que si on peut cotiser à ces régimes et donc, que si on occupe un emploi rémunéré. Se posait alors la question de la piètre performance du Canada et du Québec en ce domaine. Pourquoi acceptait-on ici un niveau de chômage aussi élevé ? Dans Le plein emploi: pourquoi?, l'inertie sociale face à la question de l'emploi était expliquée par un certain défaitisme de la part de tous les acteurs. Pour contrer ce défaitisme, une analyse de l'expérience des pays à hauts niveaux d'emploi s'imposait. Cette recherche a donné lieu à la parution du volume Le défi du plein emploi. Y étaient mises en lumière les conditions de réalisation du plein emploi, entre autres, la concertation entre les partenaires.

Lise a, par la suite, travaillé à développer cette concertation, d'abord à la Table nationale de l'emploi et, plus récemment, au Secrétariat à la Concertation. Elle a également participé activement à la création et aux travaux du Forum pour l'emploi, institution réunissant les partenaires privés du marché du travail qui transforme graduellement les mentalités au Québec et favorise des relations plus coopératives entre employeurs et syndicats.

L'héritage qu'elle nous laisse doit demeurer très présent dans les débats qui animent et animeront encore longtemps nos sociétés.

DIANE BELLEMARE

Société québécoise de développement de la main-d'œuvre
GINETTE DUSSAULT

Département des relations industrielles Université Laval 